\title{
Editorial for special issue on metal-based materials for energy catalysis
}

\author{
Shao-Jun Guo* (iD), Xiao-Qing Huang*(i), Qiao Zhang*(i)
}

Published online: 11 June 2020

(C) The Nonferrous Metals Society of China and Springer-Verlag GmbH Germany, part of Springer Nature 2020

We are so honored to present a special issue on the topic of "metal-based materials for energy catalysis" as Guest Editors of the journal Rare Metals. It showcases most recent research advances on metal-based energy catalysis and provides review and outlook for this area. The exhaustion of fossil energy drives the ongoing development of renewable energy conversion and storage. Featured by many intrinsic advantages, metal-based catalysts are key to the development of energy conversion and storage devices and have been at the center of extensive and intensive studies in the past few decades. Researches on metal-based catalysts have spanned from metallic alloys to oxides and nitrides, from nanoparticles to nanowires, nanosheets and frame-like morphologies, from porous structure to core/ shell structure, etc. Still, there are a wide variety of challenges in terms of scientific fundamentals and practical application yet to be solved.

The Rare Metals special issue presents a collection of reviews and research articles focusing on metal-based materials for energy catalysis. It includes two reviews and nine research articles dedicated to the frontiers of metal-

\section{S.-J. Guo*}

Department of Materials Science and Engineering, College of Engineering, Peking University, Beijing 100871, China e-mail: guosj@pku.edu.cn

\section{X.-Q. Huang*}

College of Chemistry, Chemical Engineering and Materials Science, Soochow University, Suzhou 215123, China e-mail: hxq006@suda.edu.cn

\section{Q. Zhang*}

Institute of Functional Nano\&Soft Materials (FUNSOM), Jiangsu Key Laboratory for Carbon-Based Functional Materials and Devices, Soochow University, Suzhou 215123, China e-mail: qiaozhang@suda.edu.cn based catalysis, from rational design of various highly active catalysts to mechanistic analysis of structure-performance relationship. It is right time to launch a single issue centering on catalysis by noble metal and transition metal-based materials. The comprehensive reviews as well as insightful original researches will offer new path to resolving challenging questions and open up new possibilities for emerging and interesting research areas.

Porous materials with high surface area and hierarchically ordered structure have proven to be beneficial for heterogeneous catalysis. One review discussed in detail four typical kinds of metal catalysts, i.e., metal oxides, porous metals, metal nanoparticles supported on metalorganic frameworks (MOFs) and zeolites from the aspects of synthetic approaches and catalytic applications [1]. The other review focused on single nanoparticle-nanoscale shell structures including core-shell and yolk-shell, and multiple nanoparticles embedded in nanoscale shells [2]. Nanoscale shell layers with tunable physicochemical properties are advantageous in that they are able to inhibit thermal sintering and particle aggregation, and that they improve reaction kinetics by facilitating diffusion of molecules.

In order to address the drawback of corrosion of carbon black support that usually leads to the activity decay of $\mathrm{Pt}$ catalyst, one article presented the hybrid support consisting of TiN nanoparticles with good chemical stability and carbon nanotubes (CNTs) with good electronic conductivity [3]. The atomic layer deposition (ALD) approach was employed to deposit TiN nanoparticles onto CNTs; the hybrid support was then used to load Pt nanoparticles to obtain Pt@TiN/CNTs catalyst. The strong electron transfer as well as chemical coupling between $\mathrm{Pt}$ and $\mathrm{TiN}$ was 
shown to promote oxygen reduction reaction (ORR) activity and stability of Pt@TiN/CNTs relative to Pt/C.

Pd-based catalysts are the topic of considerable research as well. One report focused on electrocatalysis of ethanol oxidation reaction (EOR) by $\mathrm{PdPb}_{3}$ nanochains [4]. The exceptional EOR performances of $\mathrm{PdPb}_{3}$ nanochains relative to $\mathrm{Pd} / \mathrm{C}$ were ascribed to the tuning of reaction intermediates via the introduction of second metal $(\mathrm{Pb})$ to modulate Pd electronic structure. Meanwhile, the introduction of $\mathrm{Pb}$ as an oxophilic metal generates adsorbed $\mathrm{OH}$ species on the adjacent Pd and thus facilitates the oxidative removal of $\mathrm{CO}$ intermediates. Two reports featured $\mathrm{Pd} /$ $\mathrm{CeO}_{2}$ catalysts for $\mathrm{CO}$ oxidation [5,6]. One of them reported the influence of $\mathrm{Pd}$ chemical states on catalytic activity [5]. The Pd species exist in the form of $\mathrm{PdO}$ and $\mathrm{Pd}_{x} \mathrm{Ce}_{1-x} \mathrm{O}_{2}$, the latter of which is formed as a transition layer between $\mathrm{PdO}$ and $\mathrm{CeO}_{2}$ to accelerate the transport of active oxygen species. The valence states are 2 and between 2 and 4 for $\mathrm{PdO}$ and $\mathrm{Pd}_{x} \mathrm{Ce}_{1-x} \mathrm{O}_{2}$, respectively. The ascending trend of catalytic activity of $\mathrm{CO}$ oxidation is well in accordance with surface concentration of $\mathrm{Pd}_{x} \mathrm{Ce}_{1-x} \mathrm{O}_{2}$. The other report presented electroless chemical deposition of $\mathrm{Pd}$ species onto reduced $\mathrm{CeO}_{2}$ nanorods [6]. During the synthesis of uniform Pd nanoparticles (NPs) on $\mathrm{CeO}_{2}\left(\mathrm{Pd} \mathrm{NPs} / \mathrm{CeO}_{2}-\mathrm{ECD}\right)$, the reduced $\mathrm{CeO}_{2}$ nanorods with high concentration of $\mathrm{Ce}^{3+}$ and oxygen vacancy facilitate electron transfer to $\mathrm{Pd}$ precursors to enable nucleation and growth of Pd NPs. The prominent electronic metal-support interaction (EMSI) effect and the absence of chloride ions endow $\mathrm{Pd} \mathrm{NPs} / \mathrm{CeO}_{2}-\mathrm{ECD}$ with remarkable $\mathrm{CO}$ oxidation activity as compared to $\mathrm{Pd} \mathrm{NPs} / \mathrm{CeO}_{2}$ prepared by impregnation. The strong EMSI effect was manifested by the propensity for the oxygen species located at the $\mathrm{Pd} \mathrm{NPs} / \mathrm{CeO}_{2}$ interfaces to be reduced and by the higher anti-sintering capability of $\mathrm{Pd} \mathrm{NPs} / \mathrm{CeO}_{2}-\mathrm{ECD}$.

Non-noble metal-based bifunctional electrocatalysts with extraordinary catalytic performances toward ORR and oxygen evolution reaction (OER) have emerged as potential candidates for rechargeable $\mathrm{Zn}$-air batteries. Two research articles covered this topic [7, 8]. One report showed the Fe-polyphthalocyanine molecules anchored on carbon black (Fe-PPc@CB) as bifunctional oxygen electrocatalyst [7]. The electrocatalyst was synthesized via melt polymerization approach, where pyromellitic dianhydride formed macromolecules and $\mathrm{Fe}$ atoms were situated at the center. The presence of abundant free electrons and atomically dispersed $\mathrm{MN}_{4}$-type active sites enabled $\mathrm{Fe}$ PPc@CB to exhibit exceptional ORR and OER activities. Another article reported three-dimensional mesh-like $\mathrm{NiCO}_{2} \mathrm{O}_{4}$ nanoparticles coupled with $\mathrm{Co}-\mathrm{N}_{x}$ structure formed by annealing treatment of $\mathrm{NiCo}_{2} \mathrm{O}_{4}$ under $\mathrm{N}_{2}$ [8]. The mesoporous hybrid structure with high-speed mass transfer in conjunction with the substrate materials with high electronic conductivity due to high degree of graphitization endowed $\mathrm{NiCo}_{2} \mathrm{O}_{4} / \mathrm{CoN}_{x}$ catalyst with remarkable ORR and OER catalytic activities. What's more, multiple active sites of $\mathrm{NiCo}_{2} \mathrm{O}_{4}$ spinel structure and metal coordination sites of $\mathrm{Co}-\mathrm{N}_{x}$ structure facilitate catalytic activity.

Owing to their surface plasmon resonance properties, Au-based nanoparticles are extensively investigated in terms of surface-enhanced Raman scattering (SERS) analysis. The interparticle plasmonic coupling associated with the inhomogeneity of interparticle nanogaps size, however, needs to be avoided due to the resultant attenuation in the reproducibility of Raman signals. The SERS sensitivity and signal reproducibility of bare Au NPs and $\mathrm{Au} /$ oxide $\left(\mathrm{Au} / \mathrm{SiO}_{2}, \mathrm{Au} / \mathrm{TiO}_{2}, \mathrm{Au} / \mathrm{Fe}_{2} \mathrm{O}_{3}\right)$ heterostructured NPs were compared in one report [9]. It turned out Au NPs were not uniformly distributed on the substrate with obvious particle assembly in some regions, which causes intensity variations of Raman signals. In contrast, no interparticle plasmonic coupling appears for the Au/oxide heterostructured NPs homogeneously distributed on the substrate, indicative of high reproducibility of Raman signals. Moreover, the sensitivity of SERS analysis is dependent upon refractive index of the oxide. For Au/oxide heterostructured NPs, the electromagnetic hotspots become visible at the Au/oxide interface for SERS analysis due to the strong plasmonic coupling. The intensity of Raman signals increases as the refractive index increases, and the sensitivity of SERS analysis is the highest for $\mathrm{Au} / \mathrm{Fe}_{2} \mathrm{O}_{3}$ heterostructured NPs among the three oxides.

Photochemical water splitting as an effective energy conversion device has also garnered increasing research interest in the past years. Rational design of the semiconductor sensitized system, a class of photochemical water splitting systems, is still faced with some challenges such as recombination of electron-hole pairs. One report proposed a novel $\mathrm{WO}_{3} / \mathrm{Fe}_{2} \mathrm{O}_{3}$ heterojunction structure, grown via chemical vapor deposition, which promotes separation and migration of photogenerated electrons/holes while suppressing recombination of electrons/holes [10]. The photocurrent densities of $\mathrm{WO}_{3} / \mathrm{Fe}_{2} \mathrm{O}_{3}$ heterojunction are therefore higher than those of $\mathrm{WO}_{3}$ and $\mathrm{Fe}_{2} \mathrm{O}_{3}$.

One article in this issue reported the computational fluid dynamics simulation alongside experimental investigation conducted to examine dispersibility and suspensibility of ultrafine powder slurry [11]. The suspension characteristics of the slurry are closely correlated with the impeller type, stirring speed and impeller clearance. The ideal parameters for single-particle dispersibility and suspensibility of ultrafine $\mathrm{TiO}_{2}$ slurry are implementation of Rushton disk turbine impeller with the stirring speed of $400 \mathrm{r} \cdot \mathrm{min}^{-1}$ and impeller clearance of $0.32 \mathrm{~T}$.

We would like to express our sincere thanks to all the authors and reviewers for their great contributions to make 
the special issue reach out to researchers in this area. We wish this special issue will appeal to broader readership in the future.

\section{References}

[1] Singh BK, Lee S, Na K. An overview on metal-related catalysts: metal oxides, nanoporous metals and supported metal nanoparticles on metal organic frameworks and zeolites. Rare Met. 2020. https://doi.org/10.1007/s12598-019-01205-6.

[2] Choi I, Lee HK, Lee GW, Kim J, Joo JB. Inorganic shell nanostructures to enhance performance and stability of metal nanoparticles in catalytic applications. Rare Met. 2020. https:// doi.org/10.1007/s12598-019-01203-8.

[3] Song GT, Wang Y, Qi Y, Li WM, Zhang LX. Fabrication of titanium nitride nanoparticles onto carbon nanotubes by atomic layer deposition for utilization as Pt electrocatalyst supports. Rare Met. 2020. https://doi.org/10.1007/s12598-019-01284-5.

[4] Zhang Y, Yuan XL, Lyu FL, Wang XC, Jing XJ, Cao MH, Zhang Q. Facile one-step synthesis of $\mathrm{PdPb}$ nanochains for high-performance electrocatalytic ethanol oxidation. Rare Met. 2020. https://doi.org/10.1007/s12598-020-01442-0.

[5] Zhou GF, Ma J, Bai S, Wang L, Guo Y. CO catalytic oxidation over $\mathrm{Pd} / \mathrm{CeO}_{2}$ with different chemical states of Pd. Rare Met. 2020. https://doi.org/10.1007/s12598-019-01347-7.

[6] Chen Z, Cao FX, Gao W, Dong QC, Qu YQ. Uniform small metal nanoparticles anchored on $\mathrm{CeO}_{2}$ nanorods driven by electroless chemical deposition. Rare Met. 2020. https://doi.org/ 10.1007/s12598-019-01266-7.

[7] Cheng WZ, Liang JL, Yin HB, Wang YJ, Yan WF, Zhang JN. Bifunctional iron-phthalocyanine metal-organic framework catalyst for ORR, OER and rechargeable zinc-air battery. Rare Met. 2020. https://doi.org/10.1007/s12598-020-01440-2.

[8] Qiao MF, Wang Y, Li L, Hu GZ, Zou GA, Mamat X, Dong YM, $\mathrm{Hu}$ X. Self-templated nitrogen-doped mesoporous carbon decorated with double transition-metal active sites for enhanced oxygen electrode catalysis. Rare Met. 2020. https://doi.org/10. 1007/s12598-019-01345-9.

[9] Fan QK, Liu TZ, Li HS, Zhang SM, Liu K, Gao CB. Gold/oxide heterostructured nanoparticles for enhanced SERS sensitivity and reproducibility. Rare Met. 2020. https://doi.org/10.1007/ s12598-018-01199-7.

[10] Zhang YF, Zhu YK, Lv CX, Lai SJ, Xu WJ, Sun J, Sun YY, Yang DJ. Enhanced visible-light photoelectrochemical performance via chemical vapor deposition of $\mathrm{Fe}_{2} \mathrm{O}_{3}$ on a $\mathrm{WO}_{3}$ film to form a heterojunction. Rare Met. 2020. https://doi.org/10.1007/ s12598-019-01311-5.

[11] Wu WC, Cui J, Jiang H, Jiang HB, Li CZ. Computational fluid dynamics simulation and experimental analysis of ultrafine powder suspension. Rare Met. 2020. https://doi.org/10.1007/ s12598-019-01323-1.

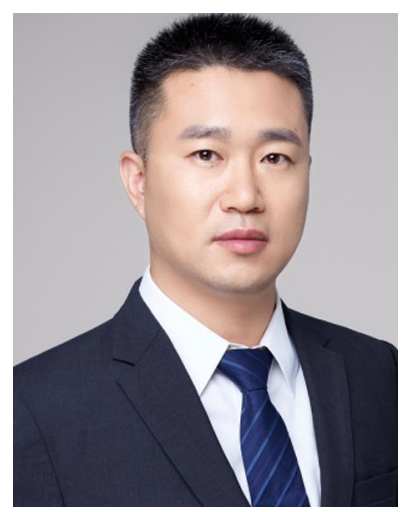

Shao-Jun Guo is a professor in the Department of Materials Science and Engineering, College of Engineering, Peking University and a Fellow of the Royal Society of Chemistry. Guo holds a BS in Materials Chemistry (2005) from Jilin University and a Ph.D. in Analytical Chemistry (2010) from Chinese Academy of Sciences. Before he was appointed a faculty member at Peking University in 2015, he did his postdoctoral research at Brown University (2011-2013) and was Oppenheimer Fellow at Los Alamos National Lab (2013-2015). His current research interests are energy catalytic materials and advanced battery materials.

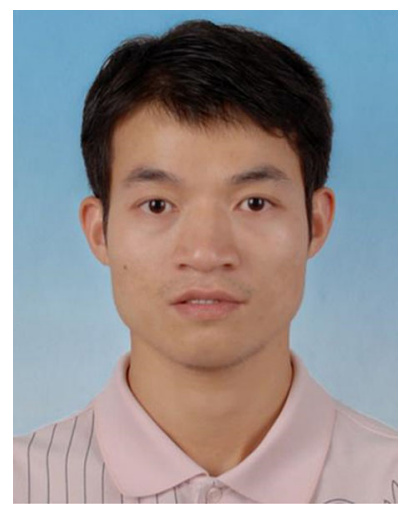

Dr. Xiao-Qing Huang is currently a Professor at College of Chemistry, Chemical Engineering and Materials Science, Soochow University. $\mathrm{He}$ obtained his B.Sc. in chemistry education from Southwest Normal University (2005) and $\mathrm{Ph} . \mathrm{D}$. in organic chemistry from Xiamen University (2011) under the supervision of Profs. Nanfeng Zheng and Lansun Zheng. Then, he joined Profs. $\mathrm{Yu}$ Huang and Xiangfeng Duan's group as a postdoctoral research associate from September 2011 to June 2014 at University of California, Los Angeles. His current research interests are in the design of nanoscale materials for electrocatalysis and heterogeneous catalysis.

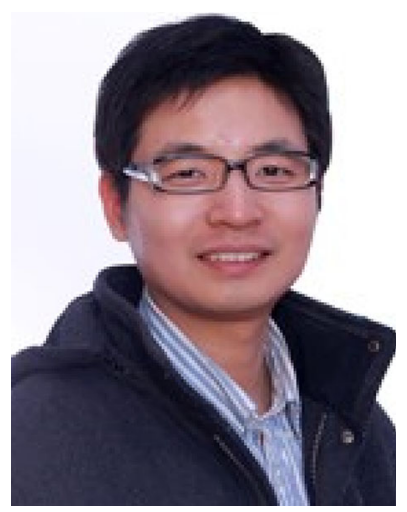

Qiao Zhang is a professor in the Institute of Functional Nano \& Soft Materials, Soochow University, China. He received his B.S. (2004) and M.S. (2007) from University of Science and Technology of China, Ph.D. from University of California, Riverside, in 2012. After being a postdoctoral fellow at University of California Berkeley, he joined Soochow University in 2014 as a professor. His main research areas are controllable synthesis of nanomaterials and their applications in heterogeneous catalysis and optoelectronics. 